\title{
The Re-Design of an Industrial Product Using the Modern Technology
}

\author{
Maria NEAGU ${ }^{\star}$
}

\begin{tabular}{l}
\hline \multicolumn{1}{c}{ A R T I C L E I N F O } \\
\hline Article history: \\
Accepted September 2019 \\
Available online December 2019 \\
\hline JEL Classification \\
C88, L86 \\
Keywords: \\
Value Analysis, Valve, \\
SuperDecisions \\
\hline
\end{tabular}

\begin{abstract}
A B S T R A C T
This paper presents the Value Analysis of a passing valve by using the Superdecisions software. The student can follow the steps of the Value Analysis and he can understand the way in which these steps are transformed in the new environment. In this way, the classical Value Analysis process takes a shape that is modern and familiar to the user.
\end{abstract}

(C) 2019 EAI. All rights reserved.

\section{Introduction}

The Value Analysis is a well known and generally used method of a product design that establishes and studies the contribution of each part and function of the product to its general cost and functionality [1, 2]. Nowadays, the Value Analysis method can be transformed in order to make use of the modern technology: the computers and the commercial softwares $[3,4]$.

This paper presents the example of a passing valve Value Analysis exercise [1] in a new and modern way. It makes use of the results of the passing valve Value Analysis [1] and, using the SuperDecisions software, it gives a new, friendly and modern shape to this well known study.

\section{The industrial product. The parts, the functions and the costs}

The example considered in this paper is the passing valve analysis developed by Nicolai and Totolici [1, page 56]. Figure 1 presents the technical drawing of the valve, while Table 1 is reloading its functions and parts analysis.

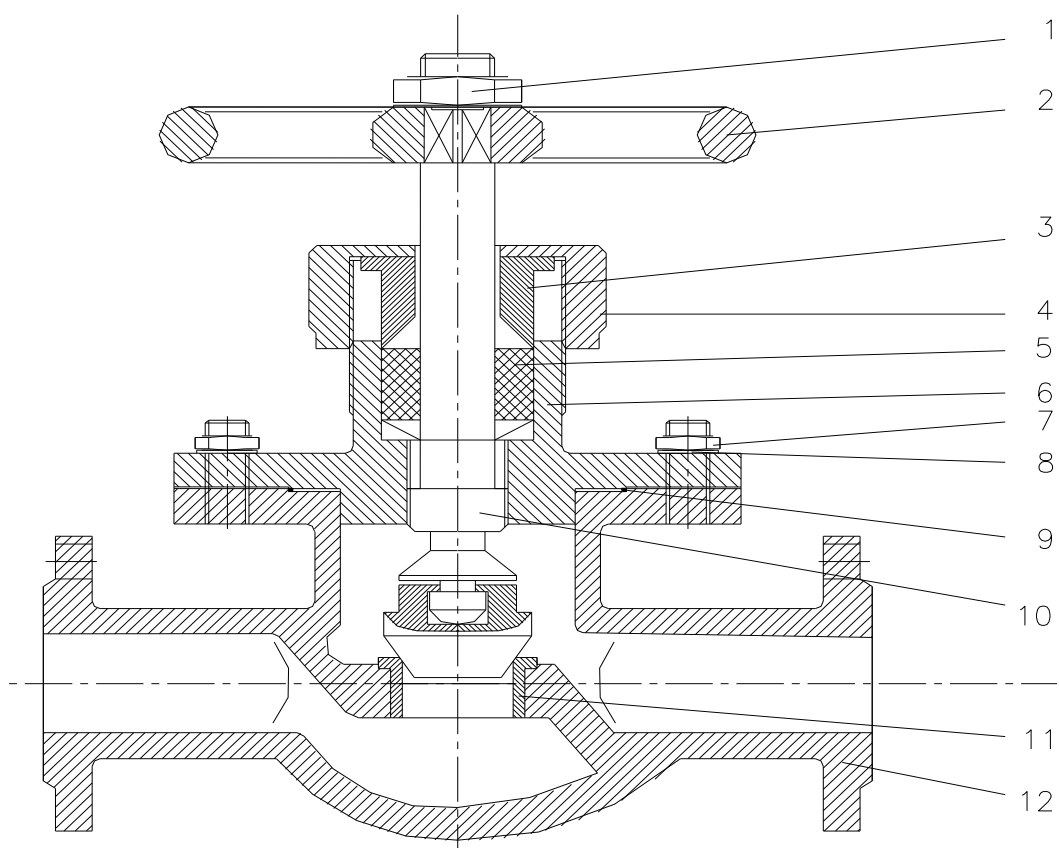

Figure 1. The passing valve technical drawing [1]

`Dunarea de Jos University of Galati, Romania. E-mail address: maria.neagu@ugal.ro (M. Neagu - Corresponding author) 
Table 1 defines the seven basic functions ("x1": $\div$ "x7") of the valve [1]. It, also, presents the valve parts ("p1" $\div$ "p12"), their costs and the way in which the costs are distributed among the seven basic functions [1].

Table 1. The passing valve functions and parts. Definitions, costs [1].

\begin{tabular}{|c|c|c|c|c|c|c|c|c|c|c|}
\hline \multirow[b]{2}{*}{ Function } & $\begin{array}{l}\text { Function } \\
\text { name }\end{array}$ & & & $\begin{array}{c}\text { A } \\
(\mathrm{x} 1)\end{array}$ & $\begin{array}{c}\text { B } \\
(\mathrm{x} 2)\end{array}$ & $\begin{array}{c}\mathrm{C} \\
(\mathrm{x} 3)\end{array}$ & $\begin{array}{c}D \\
(\mathrm{x} 4)\end{array}$ & $\begin{array}{c}E \\
(x 5)\end{array}$ & $\begin{array}{c}F \\
(\mathrm{x} 6)\end{array}$ & $\begin{array}{c}G \\
(\mathrm{x} 7)\end{array}$ \\
\hline & $\begin{array}{l}\text { Function } \\
\text { definition }\end{array}$ & & & $\begin{array}{c}\text { The fluid flow } \\
\text { enable/disable } \\
\text { function } \\
\end{array}$ & $\begin{array}{l}\text { Fluid } \\
\text { flow } \\
\text { rate } \\
\end{array}$ & $\begin{array}{c}\text { Manual } \\
\text { action }\end{array}$ & $\begin{array}{l}\text { Corrosion } \\
\text { protection }\end{array}$ & $\begin{array}{l}\text { Installation } \\
\text { coupling }\end{array}$ & Information & \begin{tabular}{|c|} 
Careful \\
exterior \\
aspect
\end{tabular} \\
\hline \multirow[t]{2}{*}{ Name } & Part & \multicolumn{2}{|c|}{ Cost } & & & & & & & \\
\hline & & Lei & {$[\%]$} & & & & & & & \\
\hline $\mathrm{p} 1$ & $\begin{array}{l}\text { Half-round } \\
\text { headed screw }\end{array}$ & 1.50 & 3.00 & & & 1.50 & & & & \\
\hline p2 & Hand wheel & 3.60 & 7.21 & & & 3.60 & & & & \\
\hline p3 & $\begin{array}{l}\text { Pressure } \\
\text { gasket }\end{array}$ & 1.67 & 3.34 & 1.67 & & & & & & \\
\hline $\mathrm{p} 4$ & Dutch nut & 2.98 & 5.97 & 2.98 & & & & & & \\
\hline p5 & Rod gasket & 1.61 & 3.22 & 1.61 & & & & & & \\
\hline p6 & Cover & 4.64 & 9.29 & 4.64 & & & & & & \\
\hline p7 & Screw & 4.20 & 8.41 & & & & 4.20 & & & \\
\hline p8 & Washer & 1.22 & 2.44 & & & & 1.22 & & & \\
\hline p9 & Gasket & 1.52 & 3.04 & 1.52 & & & & & & \\
\hline p10 & Filleted rod & 5.76 & 11.53 & 1.50 & 4.26 & & & & & \\
\hline $\mathrm{p} 11$ & Valve & 3.48 & 7.00 & & 3.48 & & & & & \\
\hline p12 & $\begin{array}{l}\text { Passing valve } \\
\text { body }\end{array}$ & 17.75 & 35.55 & & & & 1.34 & 8.61 & 4.63 & 3.17 \\
\hline & The sum & 49.93 & 100 & 13.92 & 7.74 & 5.10 & 6.76 & 8.61 & 4.63 & 3.17 \\
\hline & $\begin{array}{l}\text { Function cost } \\
\text { weight }\end{array}$ & & & 27.9 & 15.5 & 10.2 & 13.5 & 17.2 & 9.3 & 6.4 \\
\hline
\end{tabular}

\section{The SuperDecisions program}

\subsection{The clusters, the subnetworks and the nodes definition}

Further, this paper is translating this example of Value Analysis in the modern environment of computer technology using the software "SuperDecisions". We obtain, in this way, a working environment familiar to the students and the researchers nowadays.

The software "SuperDecisions" requires the definition of several clusters. Figure 2 shows the definition of two clusters, "General-goal" and "Network-costs-functions"; each cluster has one or more nodes:

- The cluster "General-goal" has only one node: "Goal";

- The cluster " Network-costs-functions" has two nodes, each of them being defined as a subnetwork: "Network-costs" and "Network-functions".
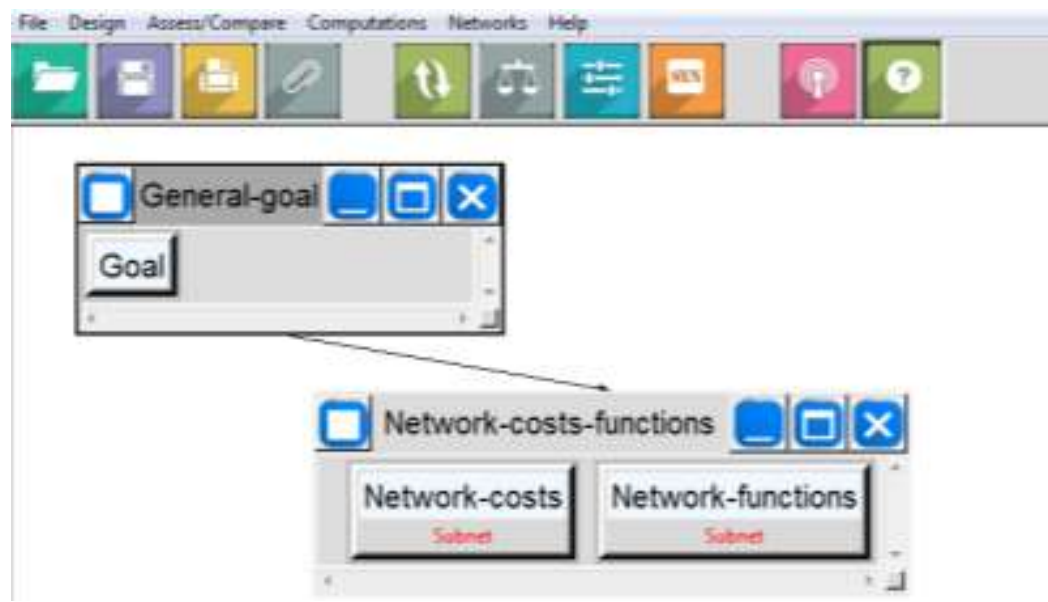

Figure 2. The SuperDecisions program. Clusters, Nodes and Subnetworks 
Figure 3 and Figure 4 show the content of the subnetworks:

- the "Network-costs" subnetwork contains three clusters:

- the "Gp" cluster has only one node: "Goal-parts";

- the "Parts" cluster has twelve nodes, each node corresponding to a part defined by Table 1: "p1":"p12";

- the "Alternatives" cluster contains the seven functions defined by Table $1:$ "x1" $\div$ "x7".

- the "Network-functions" subnetwork contains the following clusters:

- the "Gp" cluster has the "Goal-parts" node ;

- the "Alternatives" cluster has the same definition as in the "Network-costs" subnetwork.
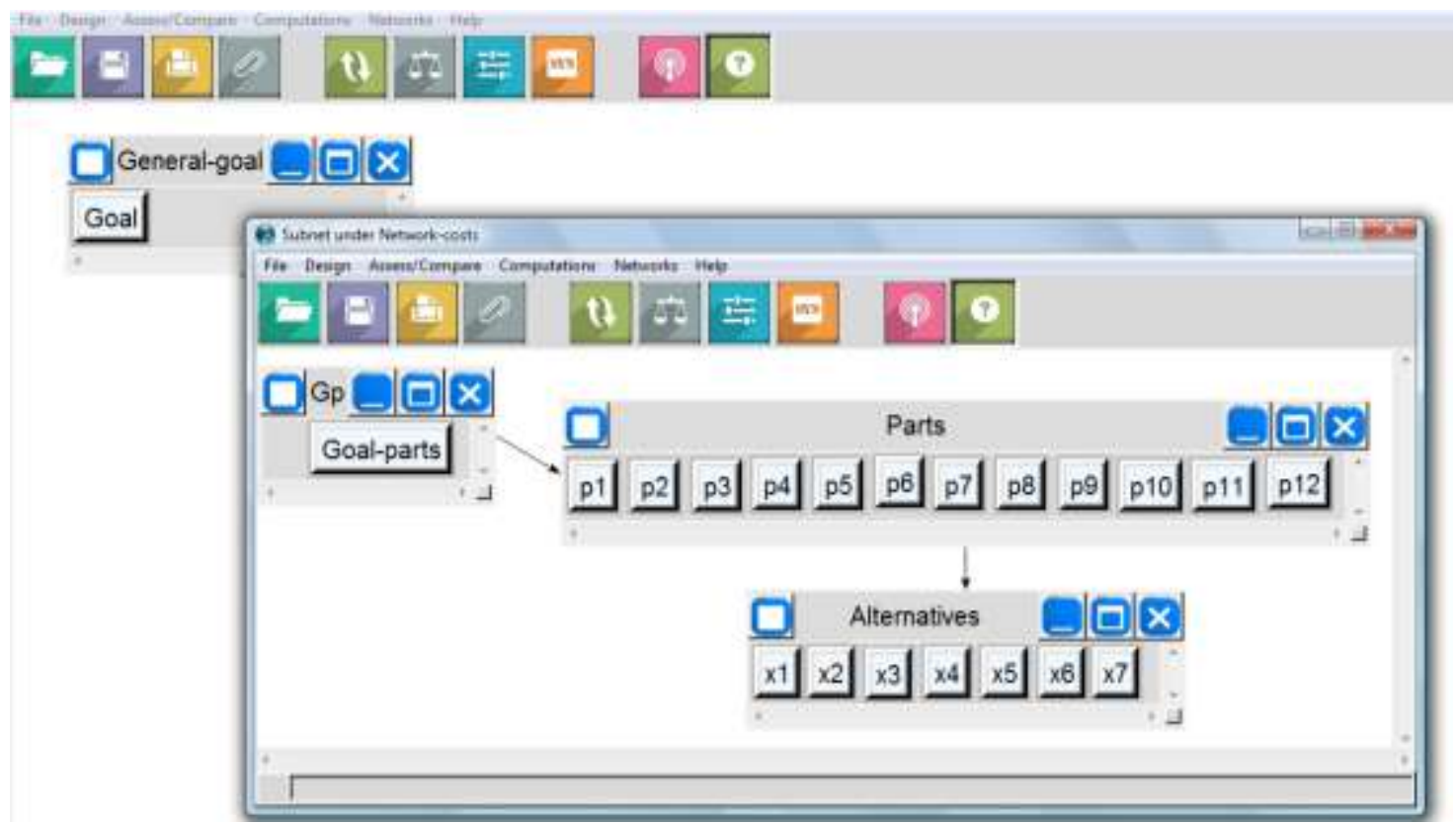

Figure 3. The "Network-costs" subnetwork

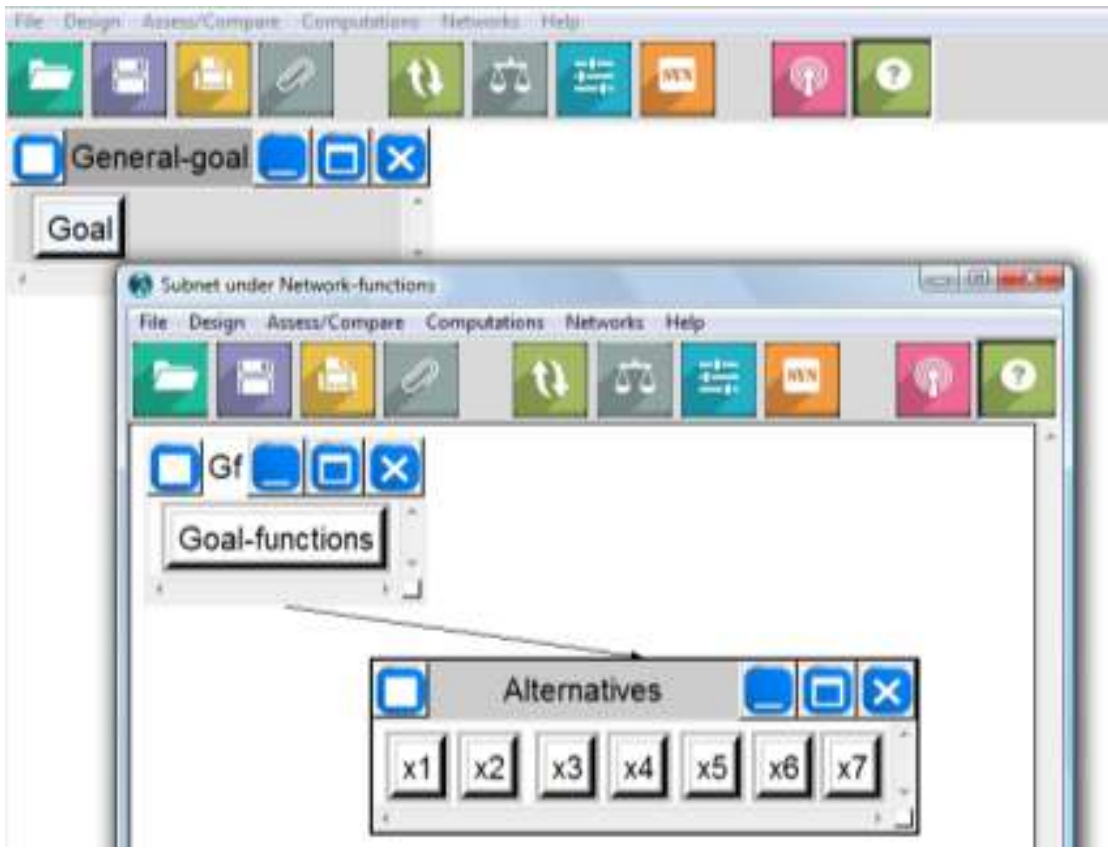

Figure 4. The "Network-functions" subnetwork

\subsection{The connections definition}

The inner-dependence of the clusters is suggested by the arrows of the Figures $1 \div 4$. The dependences of each cluster/node will be defined further, as follows:

- The "Goal-parts" node connections are presented (in red color) by Figure 5: all the " $\mathrm{p}_{\mathrm{i}}$ ", $\mathrm{i}=1 \div 12$, nodes are linked to the "Goal-parts" node. 


\section{밀eral-goal $[\square$}

Goal

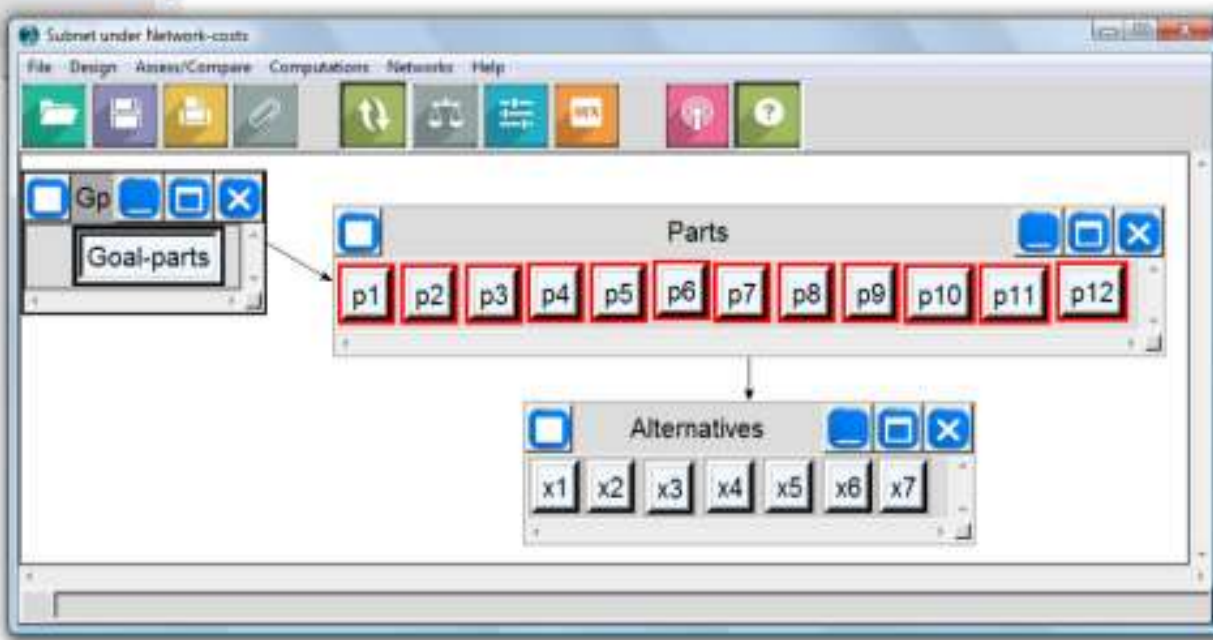

Figure 5. The node connections of the "Network-costs" subnetwork

- The nodes of the "Parts" cluster are linked as follows:

- the "p1" node is linked to the "x3" node (Figure 6a);

- the "p2" node is linked to the " $\mathrm{x} 3$ " node (Figure 6b);

- the "p3" node is linked to the " $\mathrm{x} 1$ " node (Figure 6c);

- the "p4" node is linked to the "x1" node (Figure 6d);

- the "p5" node is linked to the "x1" node (Figure 6e);

— the "p6" node is linked to the " $x 1$ " node (Figure 6f);

- the "p7" node is linked to the " $\mathrm{x} 4$ " node (Figure 6g);

- the "p8" node is linked to the " $\mathrm{x} 4$ " node (Figure 6h);

- the "p9" node is linked to the " $\mathrm{x} 1$ " node (Figure 6i);

- the "p10" node is linked to the "x1" and the "x2" nodes (Figure 6j);

- the "p11" node is linked to the "x2" node (Figure 6k);

— the "p12" node is linked to the " $\mathrm{x} 4$ ", the " $\mathrm{x} 5$ ", the " $\mathrm{x} 6$ " and the " $\mathrm{x} 7$ " nodes (Figure 61 ).

a)

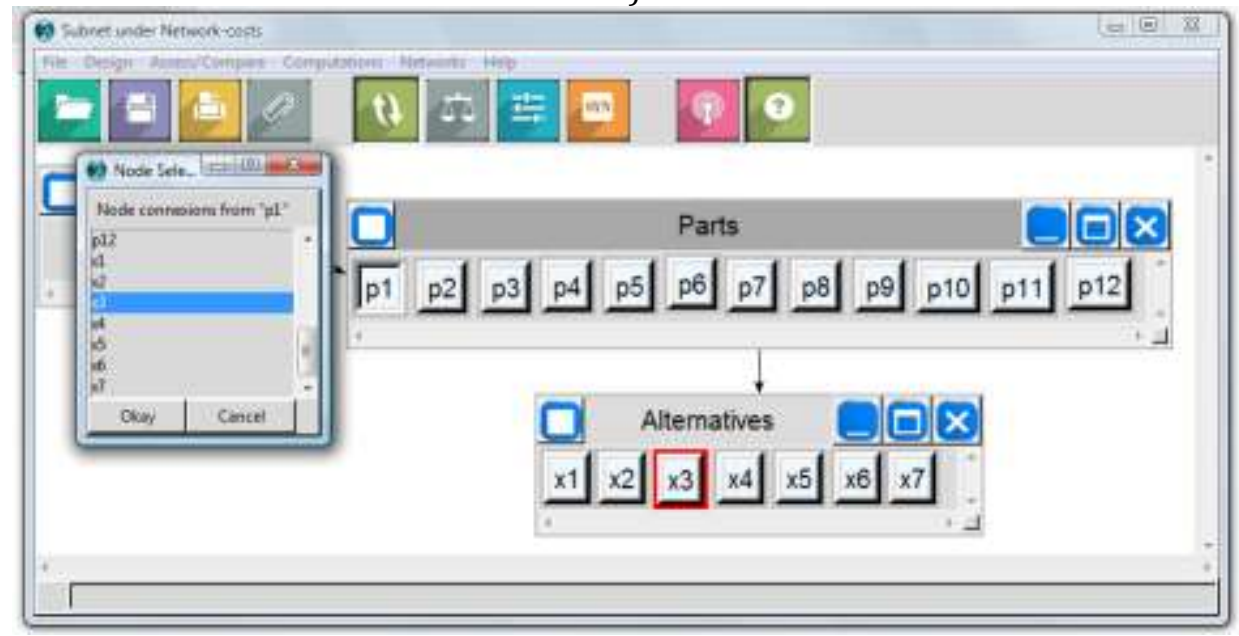

Figure 6. The "p2" $\div$ "p12" nodes connection. a) "p1"; b) "p2"; c) "p3"; d) "p4"; e) "p5"; f) "p6"; g) "p7"; h) "p8"; i) "p9"; j) "p10"; k) "p11"; l) "p12". 
b)

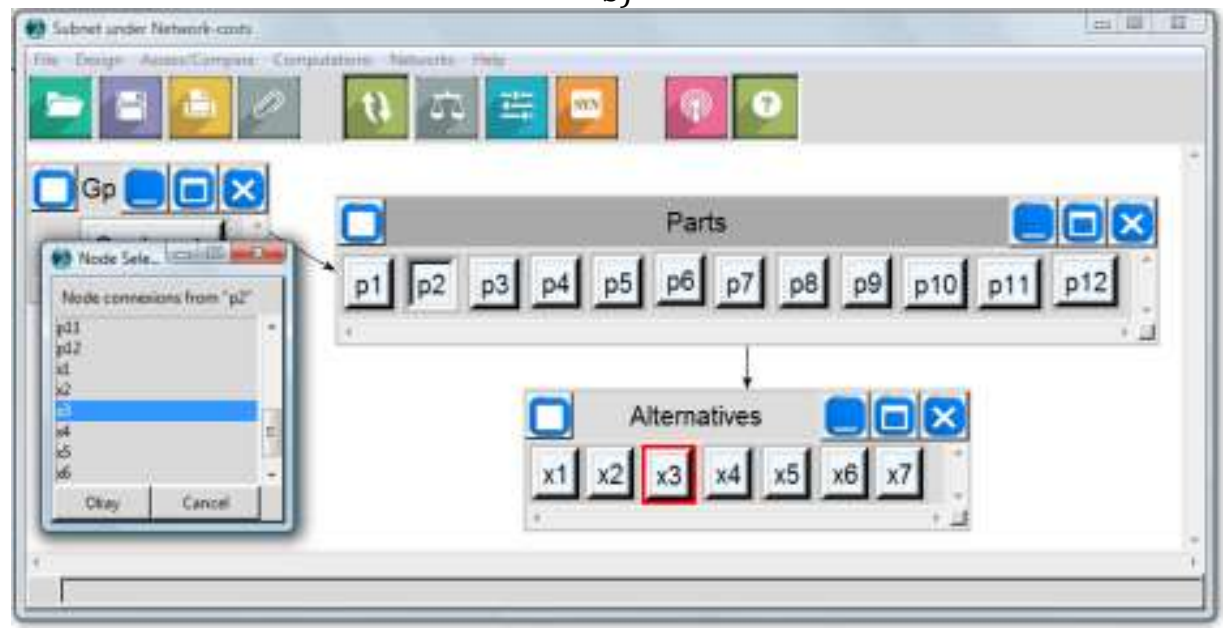

c)

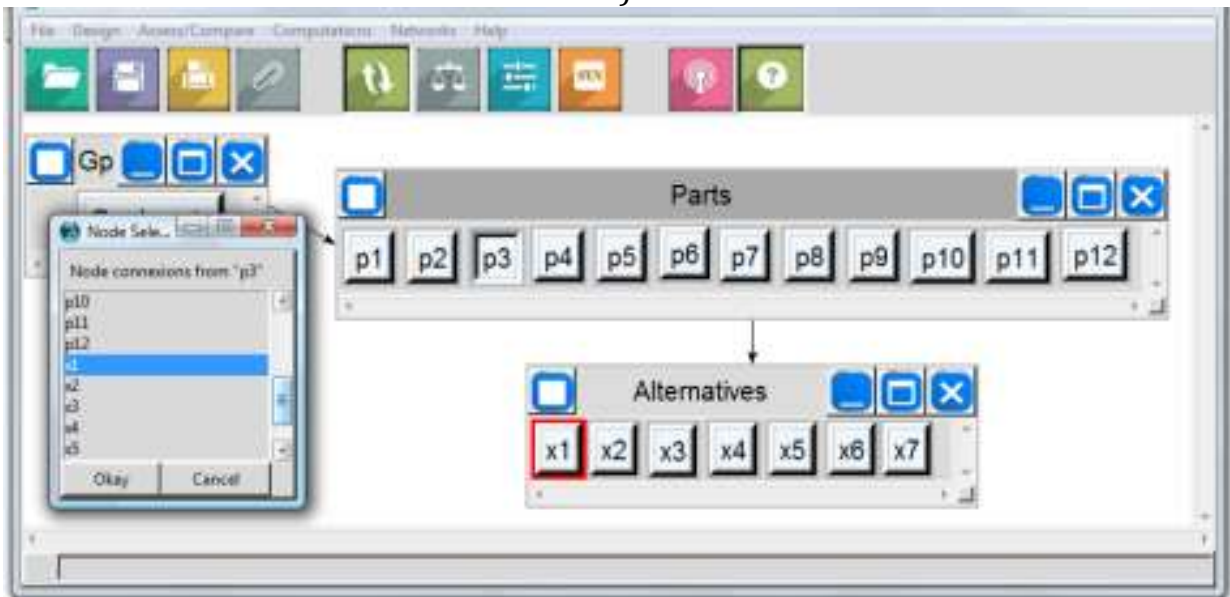

d)

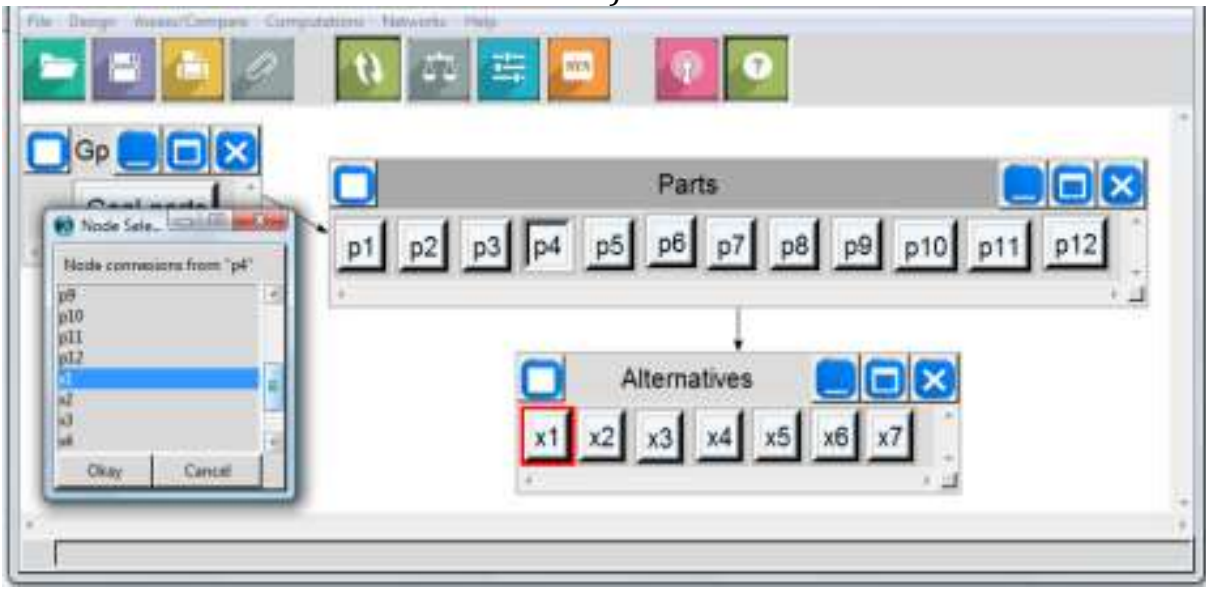

e)

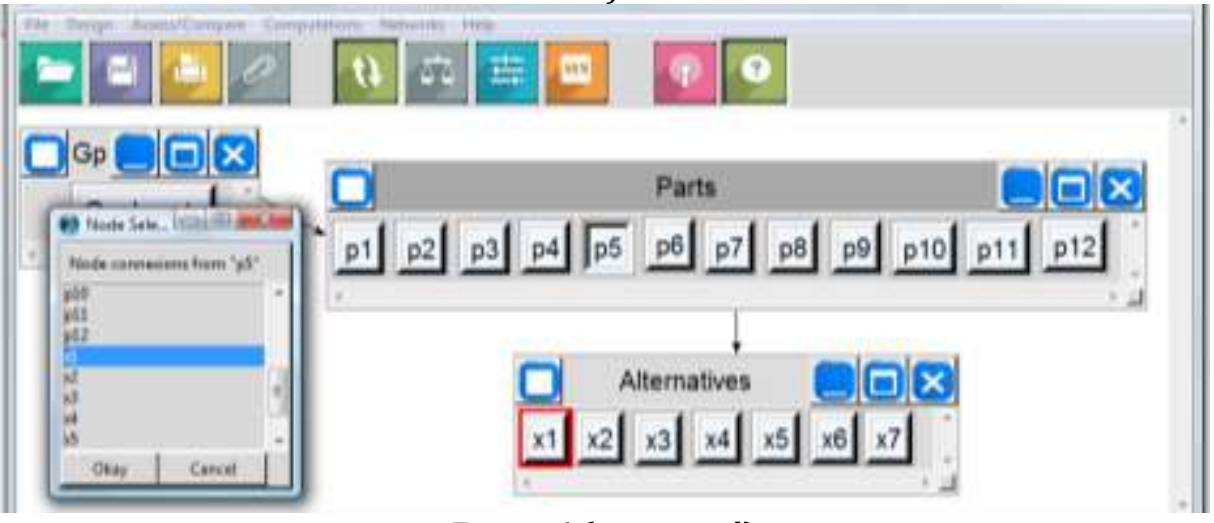

Figure 6 (continued) 
f)

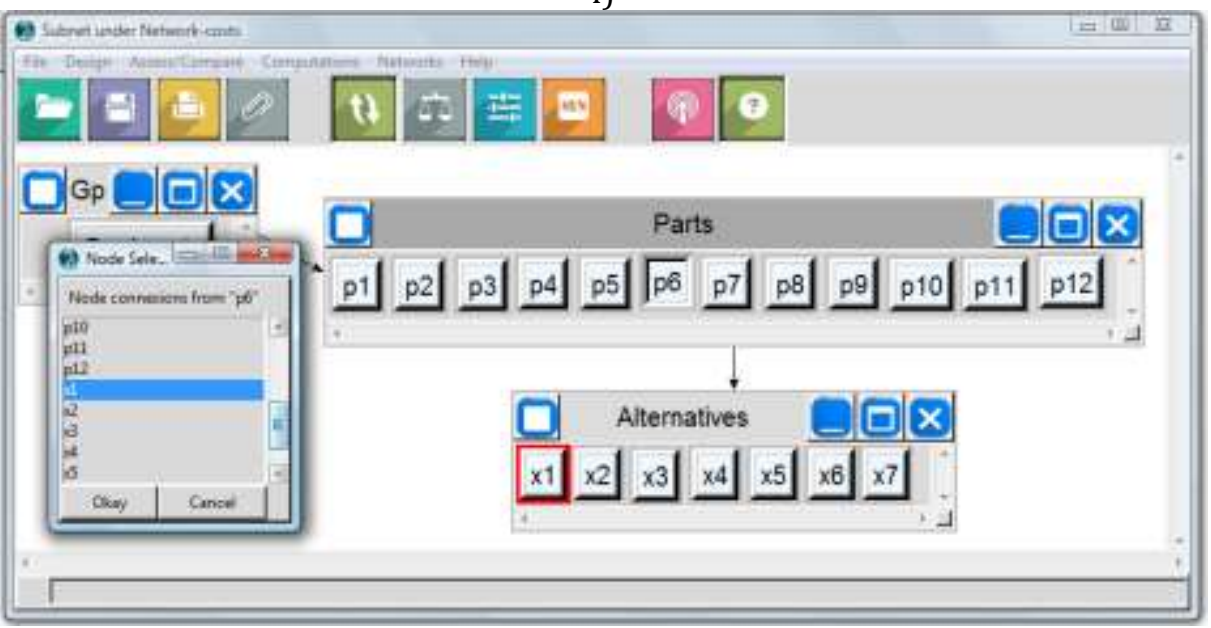

g)

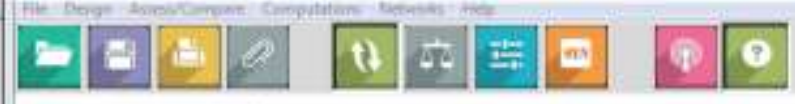

\section{口बp}

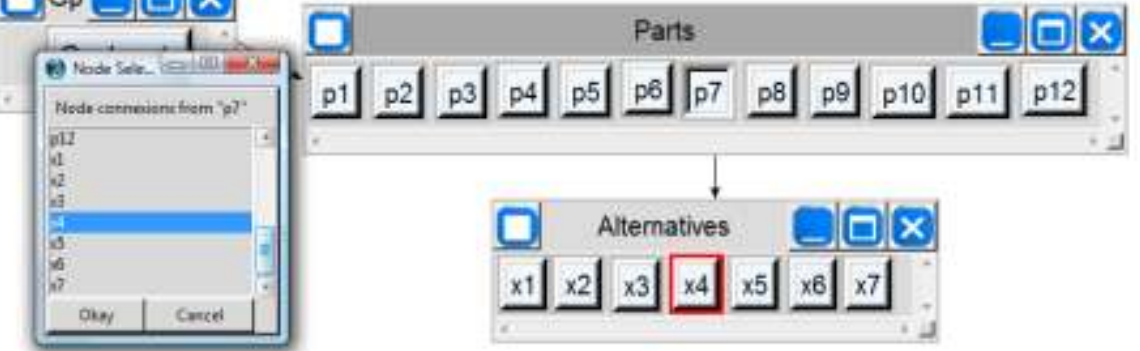

h)

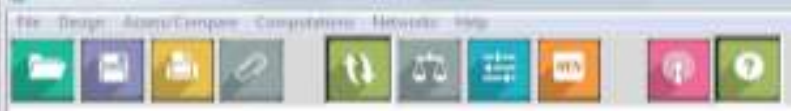

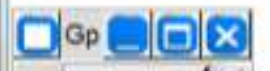

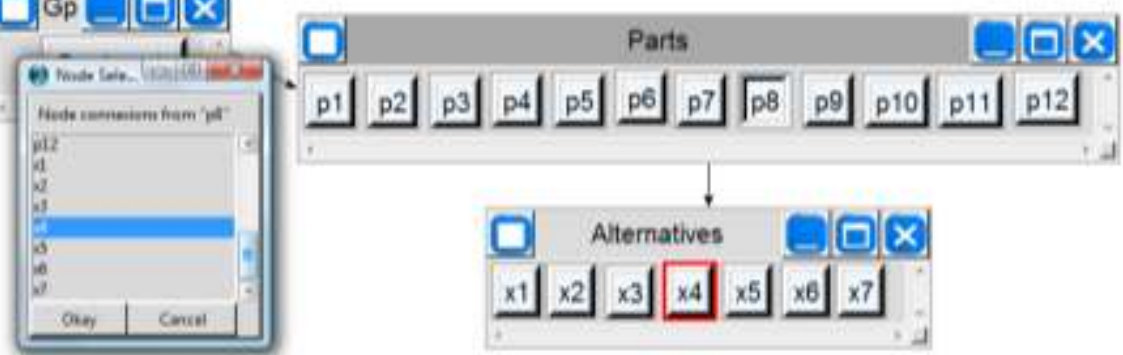

i)

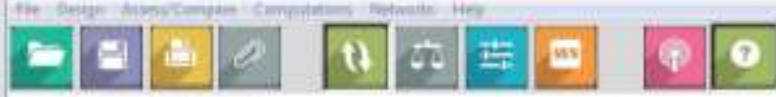

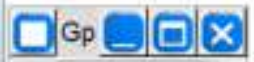

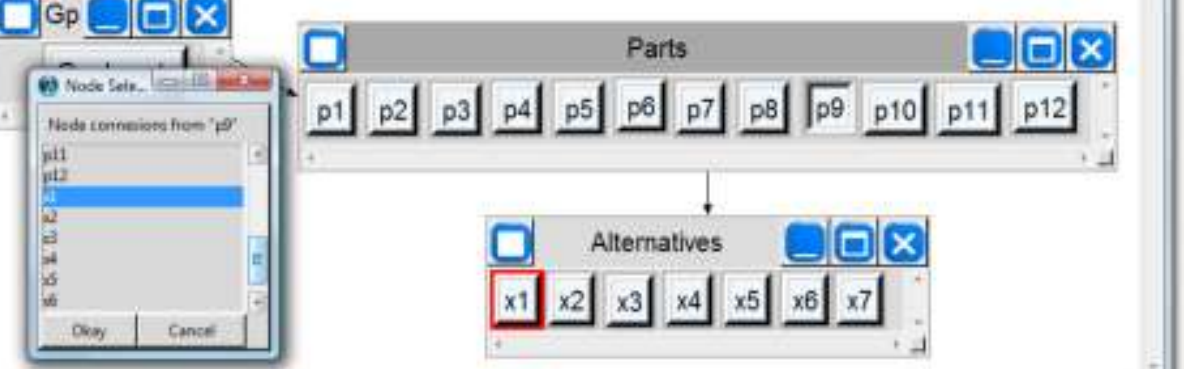

Figure 6 (continued) 
j)

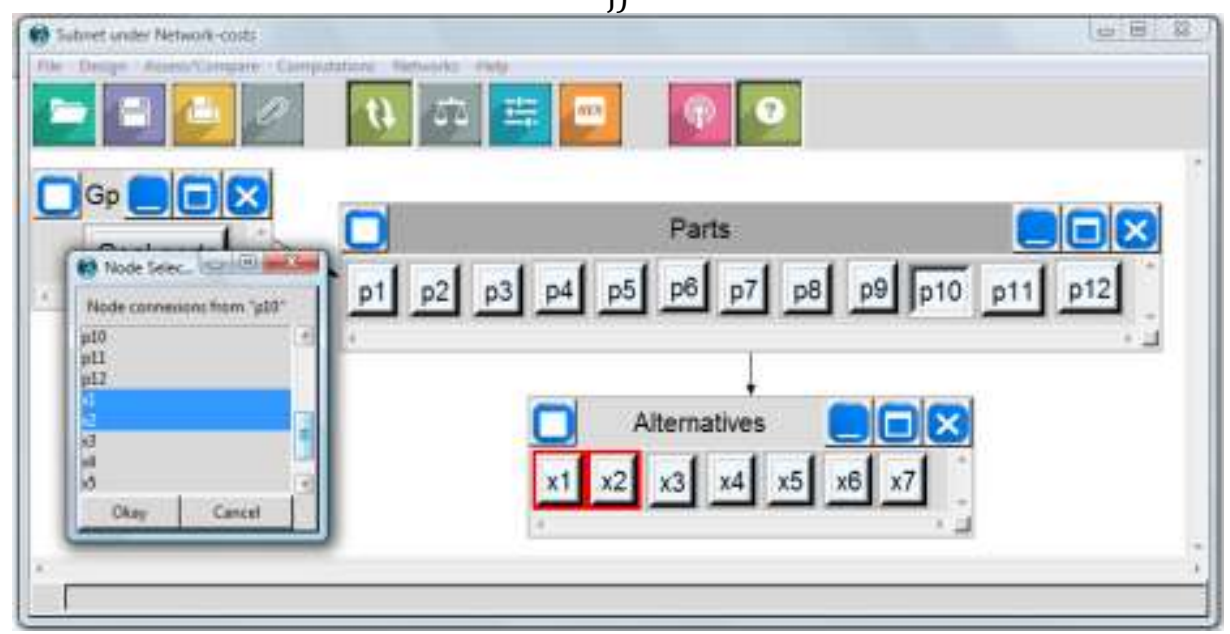

k)

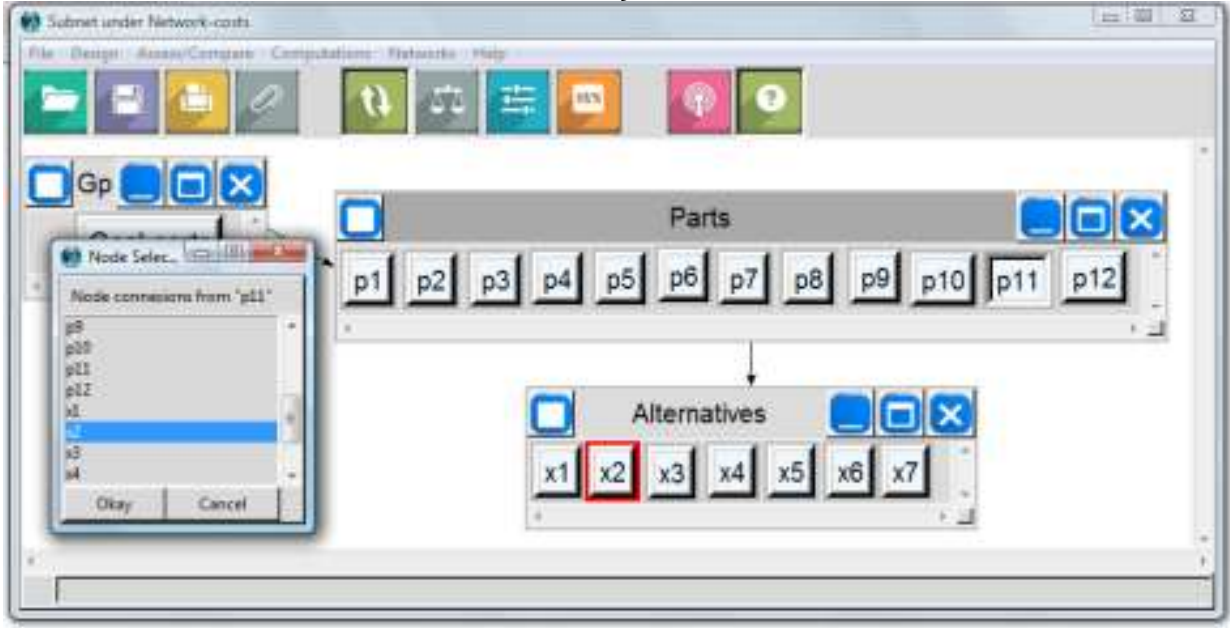

l)

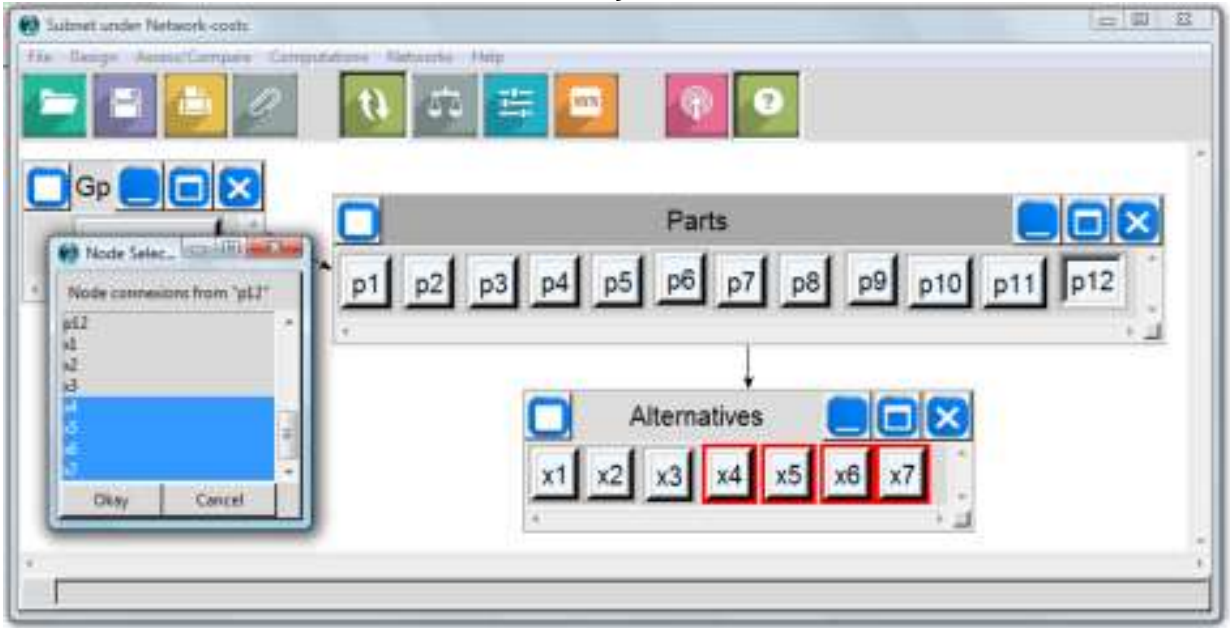

The connections of the "Network-functions" subnetwork are revealed by Figure 7. Here, we notice that the "Goal-functions" node is linked with all the nodes of the "Alternatives" cluster: "x1" $\div$ "x7".

As we can notice, the "Alternatives" cluster is contained by both subnetworks: "Network-costs" (Figure 5) and "Network-functions" (Figure 7). The seven nodes, "x1" $\div$ "x7", have different meanings in these subnetworks: in Figure 5, the " $\mathrm{x}$ " nodes refer to the cost of the functions, while in Figure 7 they refer to their importance in the functionality of the valve. 


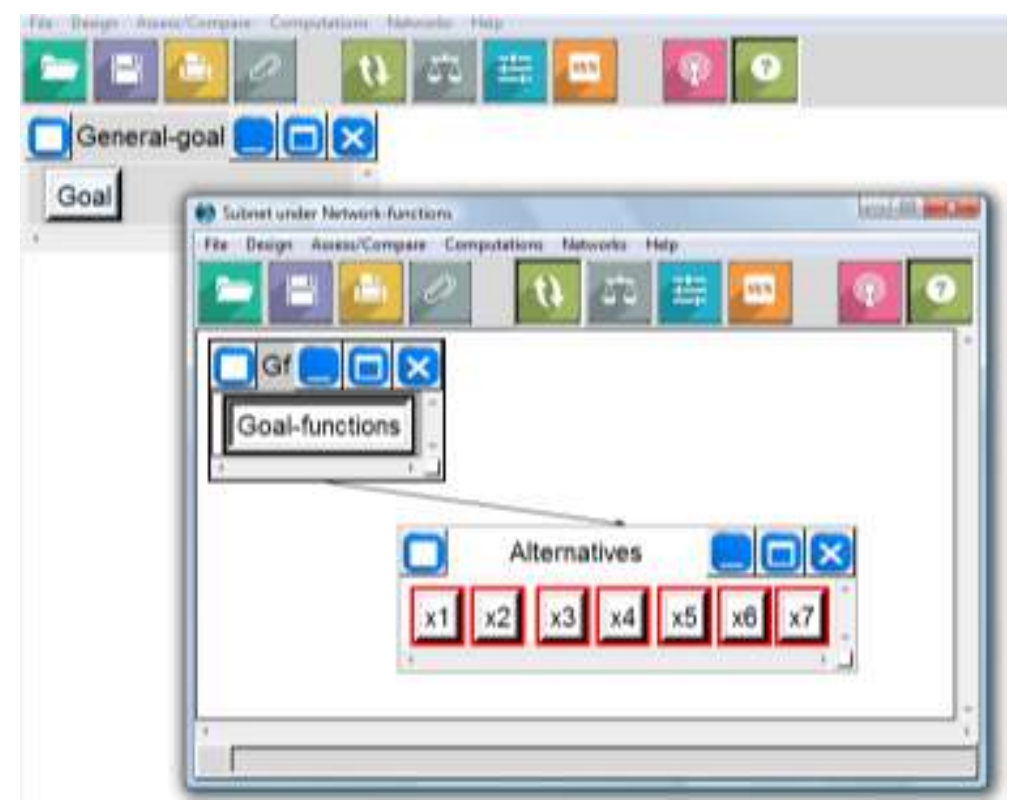

Figure 7. The connections of the "Network-functions" subnetwork

\subsection{The weights calculation}

\subsubsection{The cost weights calculation}

The weight of the parts cost can be given directly as Figure 8 suggests. The "cost" column of Table 1 is an input in the central part of Figure 8, while the weights of the part costs are calculated automatically by the SuperDecisions software. The weights of the parts cost can be read on the right table of Figure 8. functions:

From Table 1, we notice that there are only 2 parts whose cost is distributed among different

- the "p10" part — "Filleted rod" whose cost is distributed among the "x1" and the "x2" functions. Figure 9 reveals the input of the cost of the functions.

- the "p12" part — "The passing valve body" whose cost is distributed among the "x4" $\div$ "x7" functions. Figure 10 reveals the input of the "p12" part cost distribution among the functions.

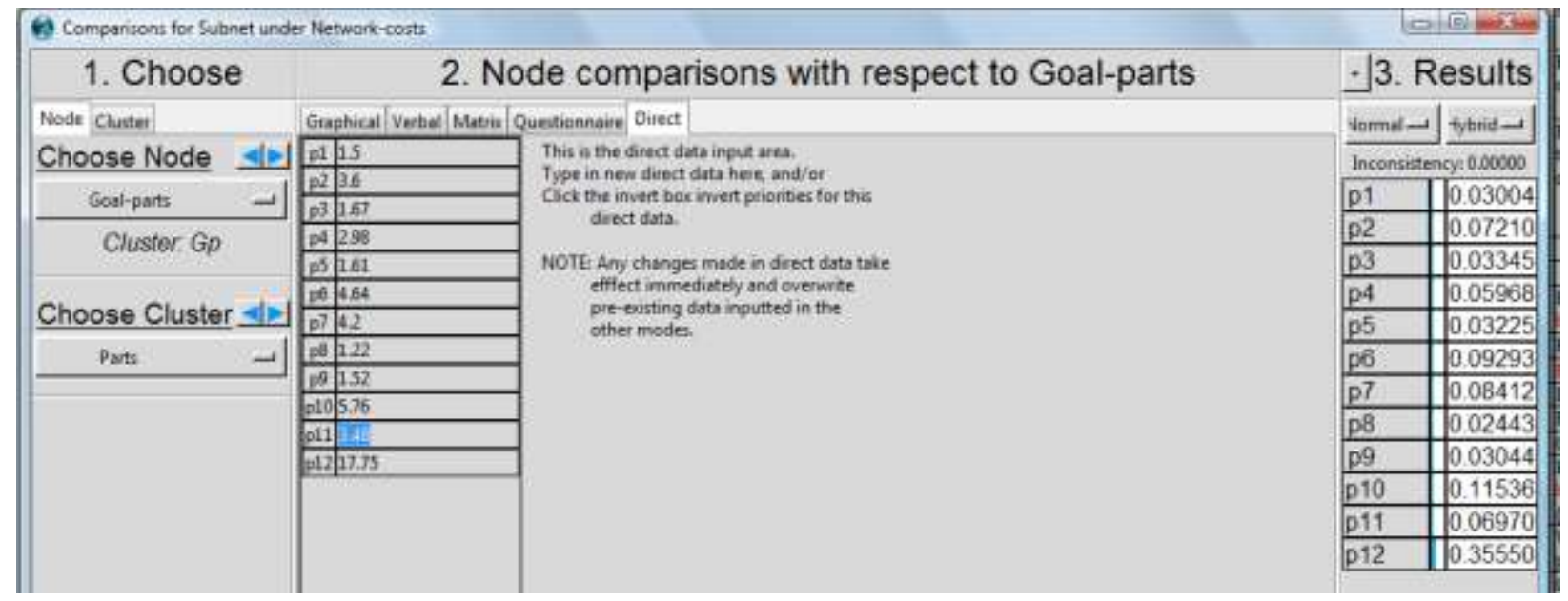

Figure 8. The weights of the parts cost

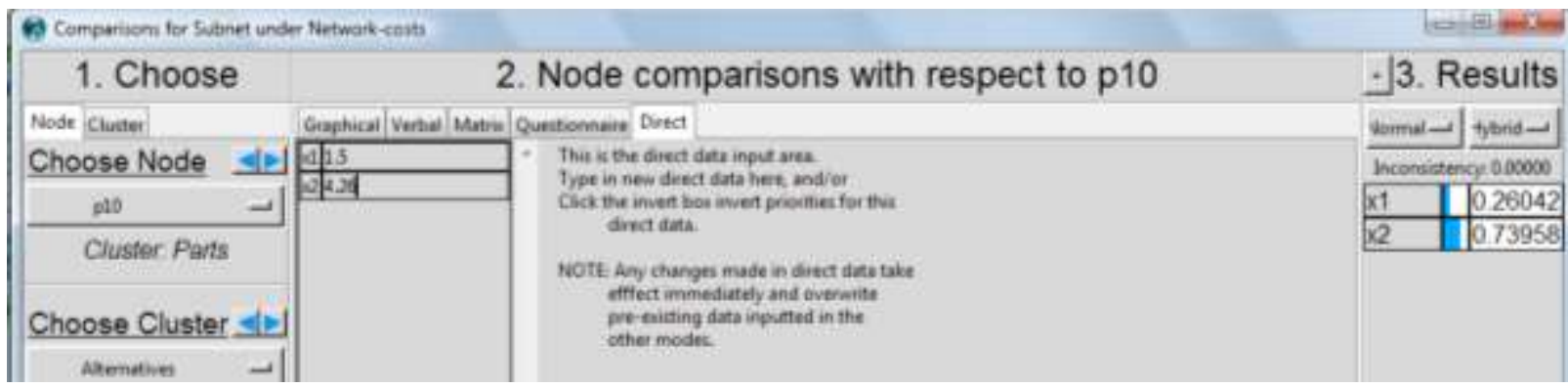

Figure 9. The weights of the "x1" and the "x2" functions for the "p10" part 


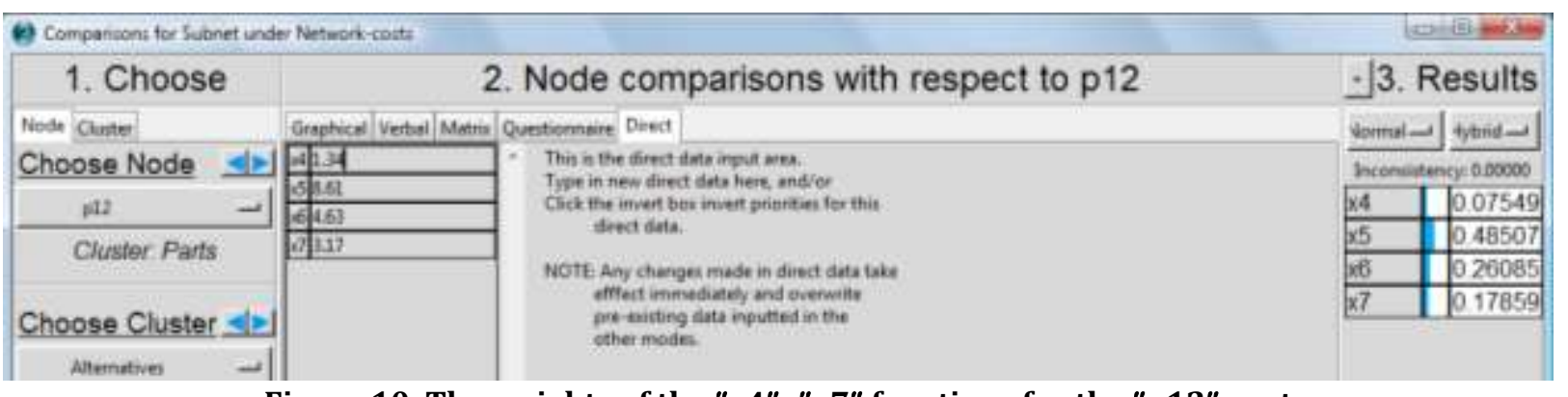

Figure 10. The weights of the "x4" $\div$ " $x 7$ " functions for the "p12" part

The priorities of the "Network-costs" subnetwork are given by the "Computations" $\rightarrow$ "Priorities" command succession and they are presented by Figure 11 in the "Normalized by Cluster" column.

\begin{tabular}{|c|c|c|c|c|}
\hline \multicolumn{5}{|c|}{ Here are the priorities. } \\
\hline Icon & Name & $\longdiv { \text { Normalized by Cluster } }$ & Limiting & $\wedge$ \\
\hline No Icon & $x 1$ & 0.27879 & 0.139395 & \\
\hline No Icon & $x 2$ & 0.15502 & 0.077509 & \\
\hline No Icon & $x^{3}$ & 0.10214 & 0.051072 & \\
\hline No Icon & $x 4$ & 0.13539 & 0.067695 & \\
\hline No Icon & $x 5$ & 0.17244 & $\longdiv { 0 . 0 8 6 2 2 1 }$ & \\
\hline No Icon & $x 6$ & 0.09273 & 0.046365 & \\
\hline No Icon & $x 7$ & 0.06349 & 0.031744 & \\
\hline No Icon & Goal-parts & 0.00000 & $\longdiv { 0 . 0 0 0 0 0 0 }$ & \\
\hline No Icon & $\mathrm{p} 1$ & 0.03004 & 0.015021 & \\
\hline No Icon & p2 & 0.07210 & 0.036050 & \\
\hline No Icon & p3 & 0.03345 & 0.016723 & \\
\hline No Icon & $\mathrm{p} 4$ & 0.05968 & 0.029842 & \\
\hline No Icon & p5 & 0.03225 & 0.016123 & \\
\hline No Icon & p6 & 0.09293 & 0.046465 & \\
\hline No Icon & p7 & 0.08412 & 0.042059 & \\
\hline No Icon & p8 & 0.02443 & 0.012217 & \\
\hline No Icon & p9 & 0.03044 & 0.015221 & \\
\hline No Icon & p10 & 0.11536 & 0.057681 & \\
\hline No Icon & p11 & 0.06970 & 0.034849 & \\
\hline No Icon & p12 & 0.35550 & 0.177749 & \\
\hline
\end{tabular}

Figure 11. The priorities of the nodes in the "Network-costs" subnetwork

\subsubsection{The functionality weights calculation}

The priorities of the "Network-functions" subnetwork can be given directly (Figure 12a) following the results of Figure 2.5 [1] or following the results of Table 3 as the AHP ("Analytical Hierarchy Process") method requires [5, 6]. Using a questionnaire with a Likert scale with maximum 9 points, Table 3 reveals the normal weights that the "x1" $\div$ "x7" functions take in the total functionality of the passing valve. These weights 
are also found in the "3. Results" part of Figure $12 \mathrm{~b}$, while the questionnaire is presented in the middle part of the Figure 12b. Further, the results of Figure 12a will be used.

Table 3. The questionnaire in the AHP method.

\begin{tabular}{|c|c|c|c|c|c|c|c|c|}
\hline Function & $\mathrm{A}(\mathrm{x} 1)$ & $\mathrm{B}(\mathrm{x} 2)$ & $\mathrm{C}(\mathrm{x} 3)$ & $\mathrm{D}(\mathrm{x} 4)$ & $\mathrm{E}(\mathrm{x} 5)$ & $\mathrm{F}(\mathrm{x} 6)$ & $\mathrm{G}(\mathrm{x} 7)$ & Normal weights \\
\hline $\mathrm{A}(\mathrm{x} 1)$ & 1 & 2 & 2 & 3 & 1 & 3 & 7 & 0.2578 \\
\hline $\mathrm{B}(\mathrm{x} 2)$ & $1 / 2$ & 1 & 1 & 2 & $1 / 2$ & 3 & 6 & 0.1636 \\
\hline $\mathrm{C}(\mathrm{x} 3)$ & $1 / 2$ & 1 & 1 & 2 & $1 / 2$ & 2 & 4 & 0.1432 \\
\hline $\mathrm{D}(\mathrm{x} 4)$ & $1 / 3$ & $1 / 2$ & $1 / 2$ & 1 & $1 / 2$ & 2 & 3 & 0.0988 \\
\hline $\mathrm{E}(\mathrm{x} 5)$ & 1 & 2 & 2 & 2 & 1 & 2 & 6 & 0.2291 \\
\hline $\mathrm{F}(\mathrm{x} 6)$ & $1 / 3$ & $1 / 3$ & $1 / 2$ & $1 / 2$ & $1 / 2$ & 1 & 2 & 0.0733 \\
\hline $\mathrm{G}(\mathrm{x} 7)$ & $1 / 7$ & $1 / 6$ & $1 / 4$ & $1 / 6$ & $1 / 6$ & $1 / 2$ & 1 & 0.0340 \\
\hline
\end{tabular}

a)

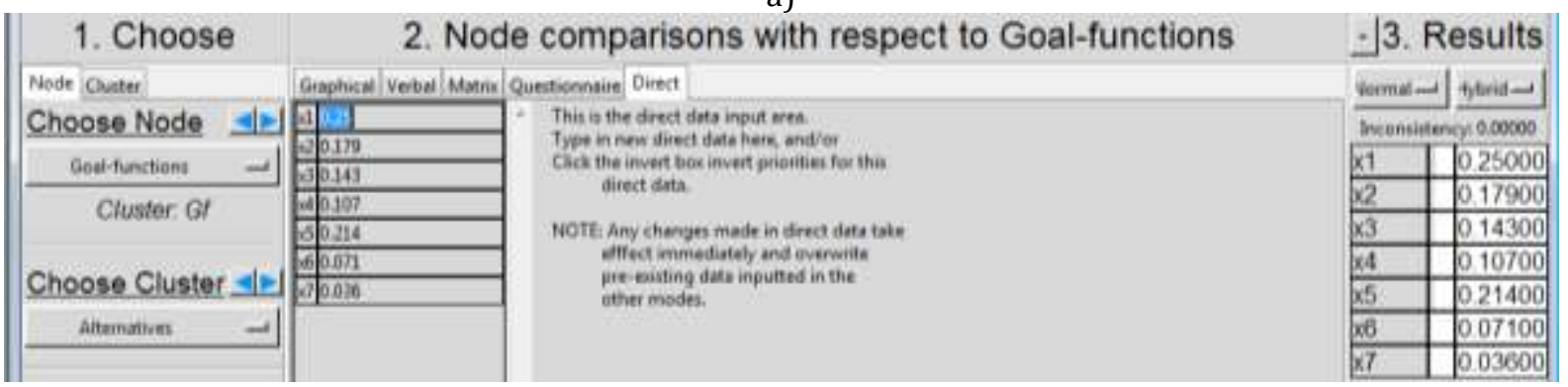

b)

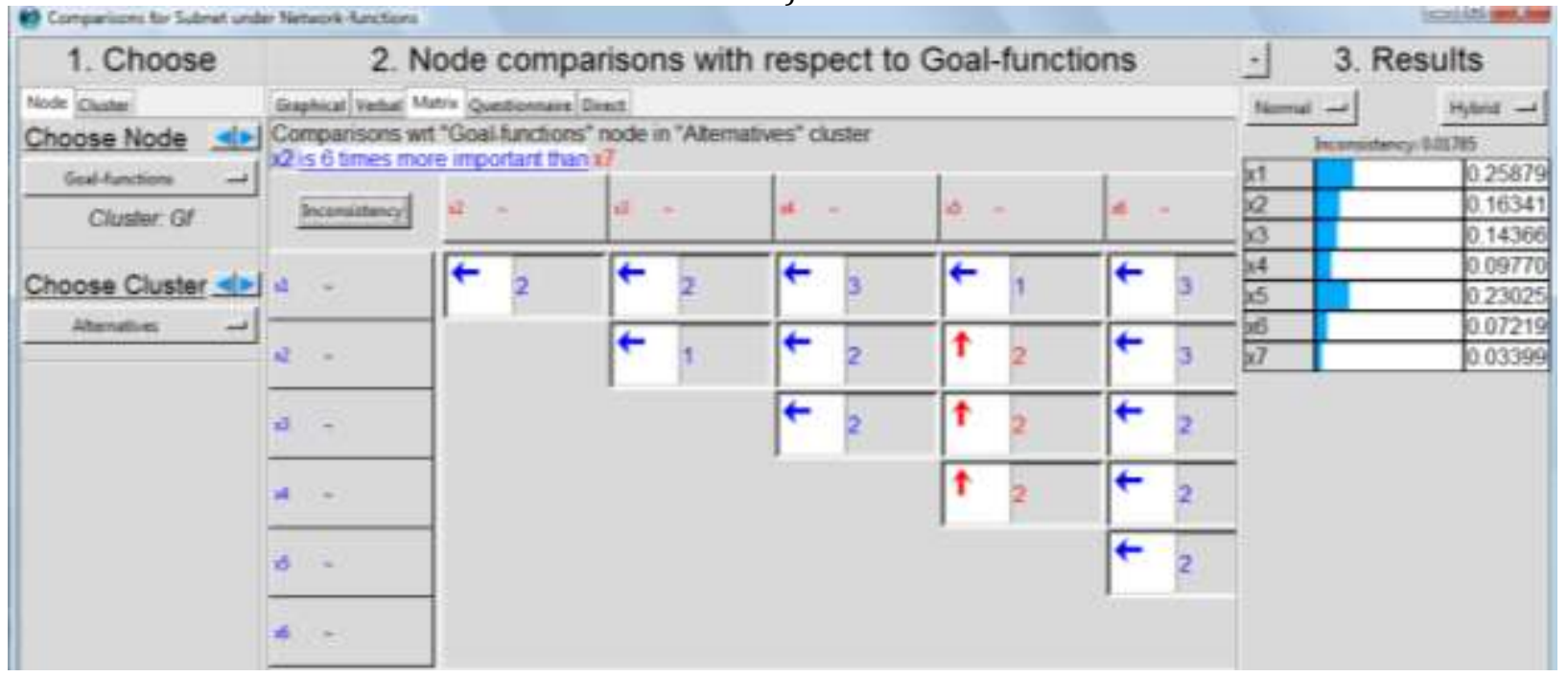

Figure 12. The functionality weights of the " $\mathrm{x} 1 " \div$ " $\mathrm{x} 7$ " functions; s) direct input; b) AHP method

The "Computations" $\rightarrow$ "Priorities" command succession gives us the priorities of the "Networkfunctions" subnetwork.

\begin{tabular}{|c|c|c|c|c|c|}
\hline \multicolumn{5}{|c|}{ Subnet under Network-functions: Priorities } & \\
\hline \multicolumn{6}{|c|}{ Here are the priorities. } \\
\hline Icon & Name & & Normalized by Cluster & $\longdiv { \text { Limiting } }$ & $A$ \\
\hline No Icon & $x 1$ & & 0.25000 & 0.250000 & \\
\hline No Icon & $x 2$ & & 0.17900 & 0.179000 & \\
\hline No Icon & $x 3$ & & 0,14300 & 0.143000 & \\
\hline No Icon & $x 4$ & & 0.10700 & 0.107000 & \\
\hline No Icon & $\times 5$ & & 0.21400 & $\longdiv { 0 . 2 1 4 0 0 0 }$ & \\
\hline No Icon & $x 6$ & & 0.07100 & 0.071000 & \\
\hline No Icon & $x 7$ & & 0.03600 & 0.036000 & \\
\hline No Icon & Goal-functions & & 0.00000 & 0.000000 & \\
\hline
\end{tabular}

Figure 13. The functionality priorities of the nodes in the "Network-functions" subnetwork 


\section{Results and discussions}

The values of the cost/functionality weights ratio of the seven functions, "x1" $\div$ "x7", can be calculated by applying the command succession "Design" $\rightarrow$ "Add/Edit Formula" (Figure 14a) and by defining the special formula given by Figure 14b.

Further, the "Computations" $\rightarrow$ "Synthesize" commands succession leads us to the values of the cost/functionality weights ratio of the seven valve functions. Figure 15 presents these values in the "Raw" column.

a)

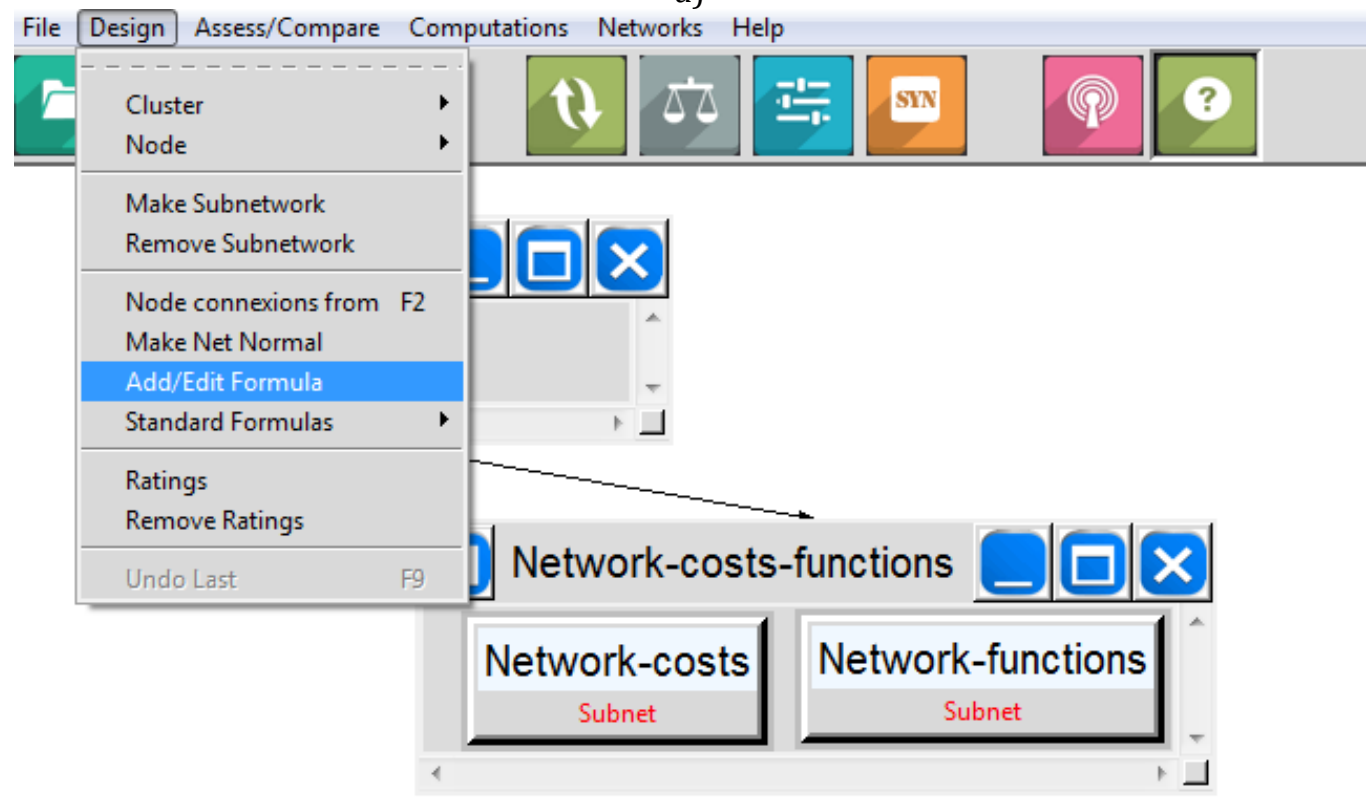

b)

\$NormalAlt (Network-costs) * [invert \$NormalAlt (Network-functions)]

Figure 14. The formula definition. a) the commands; b) the function

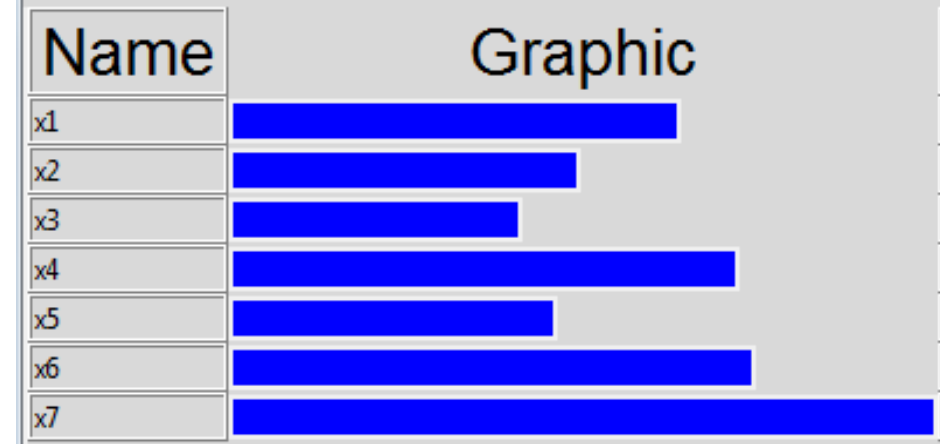

\begin{tabular}{|c||c||c|}
\hline Ideals & Normals & RaW \\
\hline \hline 0.632328 & 0.142308 & 1.115161 \\
\hline \hline 0.491056 & 0.110515 & 0.866017 \\
\hline \hline 0.405021 & 0.091152 & 0.714287 \\
\hline \hline 0.717474 & 0.161471 & 1.265323 \\
\hline \hline 0.456912 & 0.102830 & 0.805801 \\
\hline \hline 0.740570 & 0.166669 & 1.306054 \\
\hline \hline 1.000000 & 0.225055 & 1.763580 \\
\hline
\end{tabular}

Figure 15. The cost/functionality weights ratio of the "x1" $\div$ " $x 7$ " functions (the "Raw" column)

We are searching the functions whose cost/functionality weights ratio are higher than 1.0, a value that shows that the importance (the weight) of the function cost is higher than the weight of its functionality. Figure 15 shows that the "x1" (A-The fluid flow enable/disable function), the " 44 " (D-Corrosion protection), the "x6" (F-Information) and the "x7" (G-Careful exterior aspect) functions have a cost weight that is too high in the analyzed version of the product. We regain the results of the classical analysis [1]. The product design must be changed in order to reduce the cost weights of these functions.

If we want to look for a more realistic approach of the analysis, we have to calculate the real ratio of the cost/functionality weights global ratio (equation 2.18 [1]: $\mathrm{a}=\sum_{\mathrm{i}=1}^{7} \mathrm{x}_{\mathrm{i}} \mathrm{y}_{\mathrm{i}} / \sum_{\mathrm{i}=1}^{7} \mathrm{x}_{\mathrm{i}}^{2}$ ). By applying the formulas given by Figure 16a and Figure 16c, summing the "Raw" values of Figure 16b and Figure 16d, respectively, and, then, by dividing these sums, we obtain a value of 0.96 . Comparing the values of the last column (the "Raw" values) of Figure 15 to 0.96, we find, again, that the "x1", the "x4", the "x6" and the "x7" functions have a cost/functionality weights ratio that is too high. 
a)

b)

\begin{tabular}{|c|c|c|c|c|}
\hline Name & Graphic & Ideals & Normals & Raw \\
\hline$x 1$ & & 1.000000 & 0.404488 & 0.069698 \\
\hline$x 2$ & & 0.398121 & 0.161035 & 0.027748 \\
\hline$x 3$ & & 0.209569 & 0.084768 & 0.014606 \\
\hline$x 4$ & & 0.207851 & 0.084073 & 0.014487 \\
\hline$\times 5$ & & 0.529465 & 0.214162 & 0.036902 \\
\hline$\times 6$ & & 0.094463 & 0.038209 & 0.006584 \\
\hline$x 7$ & & 0.032793 & 0.013264 & 0.002286 \\
\hline
\end{tabular}

c)

$\$$ NormalAlt (Network-functions) *\$NormalAlt (Network-functions)

d)

\begin{tabular}{|l|c|c|c||c|}
\hline \multicolumn{1}{|c|}{ Name } & \multicolumn{1}{|c|}{ Graphic } & \multicolumn{1}{|c|}{ Ideals } & Normals & Raw \\
\hline \hline$x 1$ & & 1.000000 & 0.349999 & 0.062500 \\
\hline \hline$x 2$ & & 0.512656 & 0.179429 & 0.032041 \\
\hline \hline$x 3$ & & 0.327184 & 0.114514 & 0.020449 \\
\hline \hline$x 4$ & & 0.183184 & 0.064114 & 0.011449 \\
\hline \hline$x 5$ & & 0.732736 & 0.256457 & 0.045796 \\
\hline \hline$x 6$ & & 0.080656 & 0.028230 & 0.005041 \\
\hline \hline$x 7$ & & 0.020736 & 0.007258 & 0.001296 \\
\hline
\end{tabular}

Figure 16. The real cost/functionality weights global ratio calculation

a) the functionality-cost weights product formula;

b) the functionality-cost weights product values;

c) the functionality-functionality weights product formula;

d) the functionality-functionality weights product values.

\section{Conclusions}

The modern technology can be used successfully to translate in a modern environment the Value Analysis process. The analysis of a passing valve [1] is used as an example and its analysis is translated in the new environment offered by the SuperDecisions software, the program that is used in this paper in order to exemplify the advantages of the translation.

The Value Analysis process appears as an easy and a modern analysis. It becomes a process that is closer to the way in which the students and the researchers are working nowadays.

\section{References}

1. Nicolai, M., Totolici, S. (2000), "Value Analysis", Bucharest, Romania: The Office for Documentation Information for the Machine Building Industry.

2. Totolici, S., Nicolai, M. (2000), "Applicative methods of Value Analysis", Bucharest, Romania: The Office for Documentation Information for the Machine Building Industry.

3. Istrate, S., Nestian, V., Neagu M. (2018), "A company improvement analysis using the AHP and the ANP methods", Annals of "Dunărea de Jos" University of Galaţi, Fascicle I. Economics and Applied Informatics, Volume 2, pp. 47-58.

4. Nestian, V., Istrate, S., Neagu M. (2019), "A company improvement analysis using the AHP/ANP methods and the modern technology", Annals of "Dunărea de Jos" University of Galați, Fascicle I. Economics and Applied Informatics, Volume 1, pp. 63-77.

5. Neagu, M. (2016), "Concepts, methods and applications in Concurrent Engineering", Iaşi, România: Tehnopress.

6. Neagu, M. (2017) “Concurrent Engineering. Laboratories", Iași, România: Tehnopress. 